\title{
Profissionais do Sexo: Sentidos Produzidos no Cotidiano de Trabalho e Aspectos Relacionados ao HIV
}

\author{
Sex Professionals: HIV-Related Aspects and Generating Meanings in Daily Work
}

\author{
Ana Paula Gomes Esposito* \& Edna Maria Peters Kahhale \\ Pontificia Universidade Católica de São Paulo, São Paulo, Brasil
}

\begin{abstract}
Resumo
Nesta pesquisa qualitativa foi analisado o processo de construção da subjetividade de nove profissionais do sexo entrevistadas, apreendendo o processo de produção de sentidos relacionados à contextualização do HIV em seu cotidiano de trabalho. Destas, quatro eram soropositivas. Foram identificados e analisados sete núcleos de significado (Família como desencadeadora e mantedora da atividade de profissional do sexo; Identidades diversas nos diferentes ambientes frequientados: cisão trabalho $\mathrm{x}$ afetividade; Contradições vividas acerca do trabalho; AIDS como fator limitante dos prazeres em suas vidas e como empecilho para a continuidade do exercício de suas atividades; Fatores associados ao aumento da vulnerabilidade ao HIV; Serviço de Saúde como facilitador do processo de adesão ao tratamento e Entrevista como propiciadora de intervenções). Enquanto nas entrevistadas soronegativas predominaram sentimentos ambivalentes e contraditórios em relação à atividade, nas soropositivas foi observada uma polarização nos desprazeres desta atividade, inviabilizando sua continuidade após processo de adoecimento desencadeado pela AIDS.

Palavras-chave: Profissional do sexo; HIV; AIDS; psicologia sócio-histórica.
\end{abstract}

\begin{abstract}
This qualitative research analyzes the construction process of subjectivity of nine sex professionals who have been interviewed, grasping the process of generating meanings in the context of HIV in their daily work. Amongst these nine women, four were HIV carriers. Seven nodes of signification were identified and analyzed (Family as an element that causes and maintains their activity as sex professionals; Varying identities in different frequented environments: separation of work from affectivity; Contradictions that were experienced concerning work; AIDS as a limiting factor for pleasure in their lives and as an impediment to continue to practice their activities; Factors associated with the increase of vulnerability to HIV; Health Care as a facilitator in the process of adhering to treatment and the Interview as an appeasing approach for interventions). While ambivalent and contradictory feelings predominated in the seronegatives who were interviewed, a polarization towards the displeasures of the activity was observed in the seropostives, making it unfeasible to continue such activity after becoming ill by AIDS.

Keywords: Sex professional; HIV; AIDS; socio-historical psychology.
\end{abstract}

Registra-se, hoje, uma vasta literatura, tanto nacional quanto estrangeira, sobre questões ligadas ao vírus HIV, além de muitos livros e artigos tratando de assuntos referentes à prostituição. Contudo o enfoque dado às profissionais do sexo é, na maioria das vezes, de transmissoras em potencial de doenças sexualmente transmissíveis (DSTs), não sendo estas mulheres vistas em sua integralidade. Esse "desprestígio" interfere tanto na vulnerabilidade ao HIV, quanto no diagnóstico precoce e na assistência recebida (Vermelho, Barbosa \& Nogueira, 1999).

Esse cenário reflete reminiscências da história da AIDS que, em seu advento no final do século XX, a prostituta foi considerada como um "grupo de risco" na transmissão do HIV. Inicialmente, na década de 80, a AIDS, caracterizada como uma síndrome decorrente de um estado de imunodeficiência adquirida acometia principalmente os homossexuais, sendo denominada "câncer gay" pela mídia.

"Endereço para correspondência: Rua Canário, 943/124, Moema, SP, 04521-004. Fone: (11) 5042 4388. E-mail: espositoap@aol.com
Através da investigação do estilo de vida de membros sadios da comunidade homossexual dos locais com maior número de casos conhecidos de AIDS, concluíram que se tratava de uma doença infecciosa transmitida através do ato sexual. No entanto, alguns casos de imunodeficiência adquirida também foram encontrados em usuários de drogas endovenosas, heterossexuais com história de transfusão sanguínea e em crianças filhas de usuárias de drogas e prostitutas, descobrindo-se a transmissão sanguínea e vertical. Ao se associar a AIDS a um determinado estilo de vida, impôs-se a noção de grupo de risco, ligada aos subgrupos afetados. Esta posição, além de aumentar a discriminação e estigma dessa população e dos portadores da AIDS, faz com que as pessoas não identificadas com esses grupos subestimem seu risco de infectar-se com o HIV (Guerra, Veras \& Ribeiro, 2002).

Em 1987, os boletins epidemiológicos do Ministério da Saúde passaram a mostrar uma significativa mudança no perfil da epidemia, ou seja, aumento considerável de casos em mulheres, contribuindo para o questionamento da noção de "grupo de risco". No período de 1980 a 1987, a 
proporção era de 12,2 homens infectados para uma mulher infectada. Em 1996, essa proporção caiu para 2,6 (Ministério da Saúde, 2002a). Sendo assim, passou-se a falar de "comportamento de risco" e, posteriormente, em "situação de risco". Tal abordagem, apesar de mais abrangente e menos discriminatória que a anterior, ainda mantinha a responsabilidade centrada no indivíduo, pois caberia a ele identificar e evitar a situação, mantendo-se a lógica da culpabilidade.

Foi a partir do conceito de vulnerabilidade que fatores sociais e culturais passaram a ser priorizados, tais como as relações de gênero e de poder (social, cultural, econômico ou político). Mais especificamente, o risco de exposição do indivíduo à infecção pelo HIV aumenta à medida que ele não apresenta condições de fazer valer sua intenção, devido a fatores mais poderosos do que sua capacidade de agir contra a AIDS. Barros (2002) salienta que o conceito de vulnerabilidade traz à tona a inter-relação de fatores individuais, sociais e políticos como facilitadores ou dificultadores de exposição de uma pessoa ou população ao HIV, ou seja, o conceito de vulnerabilidade social e coletiva abrange aspectos sociais mais amplos, desencadeando ações governamentais e não-governamentais para for talecer as populações tidas como mais vulneráveis ao HIV.

As conseqüências dessa nova postura podem ser observadas nos dados dos Boletins Epidemiológicos do Brasil e do Município de São Paulo. No Brasil, até o ano de 1998, o número de casos novos, tanto de homem quanto de mulher, eram crescentes ano a ano, passando a decrescer a partir de 1999. Em 1998, o número de casos novos atingiu 16.738 nos homens e 8.079 nas mulheres (2,1 homens infectados para uma mulher infectada). Já em 2001, a quantidade foi de 8.605 e 5.080 casos, respectivamente $(1,7$ homem infectado para uma mulher infectada). Contudo a razão entre os sexos, ou seja, a proporção de homem/ mulher infectada tem diminuído ano a ano, apontando para uma feminilização da doença (Ministério da Saúde, 2002a). No Município de São Paulo, os dados têm seguido a mesma tendência. Em 1998, o número de casos novos atingiu 2.871 nos homens e 1.425 nas mulheres - razão 2 , O - e em 2001 a quantidade foi de 1.865 e 992, respectivamente razão 1,9 (Secretaria Municipal de Saúde, 2003).

Dentro desta perspectiva, o Centro de Referência DST/ AIDS Santo Amaro (CR Santo Amaro) realiza encontros grupais para mulheres, profissionais do sexo. Eles são coordenados por uma equipe multidisciplinar (médico, psicólogo, assistente social e educador em saúde), com periodicidade mensal, abertos (sem um número preestabelecido de participantes) e temáticos. A metodologia utilizada é a da prevenção dialogada, que possibilita a um grande número de pessoas, sobretudo de grupos mais vulneráveis, conhecer sua realidade e pensar criticamente as dimensões que colocam essas pessoas numa situação de maior vulnerabilidade, facilitando práticas protegidas, o exercício da cidadania e o cuidado da saúde de forma integral.

Em novembro de 2002, após um ano de existência dos grupos das mulheres profissionais do sexo, ao ser feito um levantamento de prontuários para avaliar os benefí- cios alcançados nesses encontros no que se refere à prevenção de DST/AIDS, e, mais especificamente, dados referentes a sorologia para o HIV, hepatites B e C; presença ou não de DSTs; freqüência às consultas médicas e vacinação da hepatite B nos casos indicados, foi constatado que no CR Santo Amaro, até este período, haviam sido matriculadas 259 mulheres profissionais do sexo. Destas, 161 participaram pelo menos uma vez do Grupo de Prevenção, e, quanto ao HIV, 17 eram soropositivas $(6,56 \%)$. Quanto ao grupo, todas as mulheres eram soronegativas.

No CR Santo Amaro existe um trabalho sistemático de prevenção de DST/AIDS com essa população, contudo o de assistência precisa ser repensado. Das 17 mulheres soropositivas, 4 abandonaram o tratamento, 5 estão há mais de seis meses sem comparecerem à instituição, 1 faleceu, 4 recusaram atendimento, estando apenas 3 em acompanhamento regular. Estes dados são contrastantes com a vinculação de outros soropositivos usuários do serviço, bem como das profissionais do sexo soronegativas. Esta realidade nos direciona para uma necessidade de melhor conhecimento desta clientela (mulheres profissionais do sexo soropositivas) e das implicações psicossociais que a soropositividade acarreta em seu cotidiano, para podermos intervir de forma estratégica e eficaz.

Alves (2001) fez um estudo com cirurgiões-dentistas portadores de HIV com o objetivo de obter relatos sobre seu relacionamento com pacientes e demais pessoas de seu convívio social e conhecer suas necessidades e receios. Foi analisado se tais profissionais continuam ou não exercendo sua profissão, as implicações em comunicar ou não a seus pacientes, o receio de serem identificados como portadores do HIV e as conseqüências em sua vida pessoal e profissional, além do temor de necessitar mudar de atividade. Apesar do profissional de saúde poder continuar exercendo sua profissão enquanto estiver em condições físicas e psicológicas para tal, utilizando, como qualquer outro profissional, os equipamentos de biossegurança, foi observado um pavor de serem identificados como soropositivos, além de uma grande preocupação em relação às possíveis conseqüências que este fato acarretaria em sua vida pessoal e na continuidade de sua atuação profissional.

Nesse sentido, no que se refere às profissionais do sexo, a questão torna-se ainda mais delicada, visto que a atividade sexual é seu instrumento de trabalho. Sabemos que, adotando cuidados de biossegurança no primeiro caso e utilizando, de forma correta, o preservativo no segundo, as chances de uma transmissão tornam-se quase nulas. Todavia, o histórico da epidemia do HIV e seu estigma que se perpetua nos dias atuais, contradizem a lógica deste raciocínio. Sendo assim, o eventual abandono da profissão após o diagnóstico pode representar, além de uma perda adicional dentro do leque de perdas que o HIV acarreta uma ruptura na saúde mental do indivíduo. Dessa forma, compreende-se que a atividade profissional está intrinsecamente relacionada à qualidade de vida e de saúde do cidadão. 
Segundo Kahhale (2003), a prática profissional do psicólogo deve abarcar projetos de intervenção que envolvam redimensionamento e reestruturação de sentidos e projetos de vida, permitindo a apropriação da subjetividade individual e social.

Neste estudo, é analisado o processo de construção da subjetividade individual e social das profissionais do sexo entrevistadas, visando apreender o processo de produção de sentidos no que se refere à contextualização do HIV em seu cotidiano de trabalho. Este estudo também se propõe a levantar questões para um programa de intervenção no Centro de Referência em DST/AIDS de Santo Amaro, objetivando contribuir para melhoria da assistência às profissionais do sexo soropositivas e sua adesão ao serviço.

Foi utilizado o referencial teórico da Psicologia Sóciohistórica. Dentro dessa abordagem, a linguagem é dotada de significados sociais, históricos e ideológicos, adquirindo um sentido pessoal construído pelo indivíduo. $\mathrm{O}$ discurso permite ter acesso ao desenvolvimento do psiquismo, como resultado da relação dialética entre atividade-consciência-identidade. No âmbito da clínica e da pesquisa, entende-se que a fala do sujeito expressa muito mais do que uma resposta ao estímulo apresentado, sendo uma construção histórica. A Psicologia Sóciohistórica atribui ao sujeito a capacidade de ressignificar seus processos patológicos, reconhecendo o caráter constitutivo das patologias na história do sujeito e de seus sistemas de relação, promovendo ações transformadoras (Aguiar, 2001).

\section{Método}

\section{Local}

Este estudo foi realizado no Centro de Referência DST/ AIDS Santo Amaro, que atende pessoas acometidas de DSTs, portadores do HIV, além de desenvolver trabalho de prevenção e assistência junto às populações vulneráveis ao HIV (usuários de drogas injetáveis, profissionais do sexo e homens que fazem sexo com homens).

\section{Participantes}

A pesquisa foi realizada com 9 mulheres, matriculadas no CR DST/AIDS Santo Amaro, que estavam trabalhando ou já haviam trabalhado como profissionais do sexo. Cabe ressaltar que todas as profissionais do sexo soropositivas em tratamento na unidade foram entrevistadas. As idades variaram entre 21 e 50 anos. Não participaram da pesquisa mulheres com menos de 18 anos, pois nesta faixa etária a comercialização do sexo é considerada crime. A escolaridade oscilou entre primeiro grau incompleto e segundo grau completo. Quatro entrevistadas eram soropositivas. Destas, nenhuma estava trabalhando como profissional do sexo. Uma estava trabalhando em casa de família, duas estavam vivendo do benefício do auxíliodoença e a outra estava sem renda. As demais entrevistadas não eram portadoras do HIV e exerciam suas atividades como profissional do sexo. Três trabalhavam em boate e duas na rua. A remuneração girava em torno de 1.500 a 3.000 reais por mês. Quanto à situação conjugal, quatro eram separadas, três eram solteiras, uma era viúva e uma das entrevistadas estava em processo de separação no momento da entrevista, concretizado algumas semanas depois. Seus Estados de origem eram: São Paulo (04), Bahia (O2), Pernambuco (01), Paraná (O1) e Minas Gerais (01).

Para garantia do anonimato, foram utilizados nomes fictícios para as entrevistadas, sendo omitidos dados que poderiam identificá-las.

\section{Instrumentos}

\section{Prontuários}

Foi realizado um levantamento de prontuários para a identificação das profissionais do sexo soropositivas.

\section{Entrevistas}

Os dados foram coletados usando-se como instrumento uma entrevista semidirigida em profundidade. Foi utilizado este instrumento por propiciar uma participação mais ativa do entrevistado do que o questionário ou a entrevista fechada, não dificultando tanto a sistematização dos dados quanto à entrevista totalmente aberta. Entendemos que o instrumento é apenas um meio facilitador de comunicação entre o pesquisador e o participante e que o processo de coleta de dados, sistematização, interpretação não é linear, pois os dados, ao serem coletados, já são interpretados, sendo o papel do investigado e do investigador bastante ativo e a neutralidade deste uma falácia.

A entrevista procurou abarcar questões relevantes para um maior conhecimento dessa população (dados de identificação e sócio-demográficos), tendo em vista a elaboração de estratégias de intervenção mais direcionadas e personalizadas. Também foram abordados temas considerados essenciais no processo de construção da subjetividade individual e social das entrevistadas (família, trabalho, relações interpessoais e afetivas, questões ligadas ao HIV e ao serviço de saúde, lazer, projetos de vida), tendo como foco a contextualização do HIV em seu cotidiano de trabalho.

\section{Procedimentos de coleta}

Esta pesquisa foi submetida à apreciação do Comitê de Ética em Pesquisa da Secretaria Municipal da Saúde, sendo aprovada após análise, estando em conformidade com a Resolução 196/96 do Conselho Nacional de Saúde. Foi também solicitada autorização à chefia do CR DST/AIDS de Santo Amaro para a execução da pesquisa em tal instituição, sendo permitida sua realização.

Primeiramente, foi feito um levantamento de prontuários para a identificação das profissionais do sexo soropositivas. Das 17 encontradas, apenas três estavam em tratamento na unidade, sendo então solicitado aos profissionais que estavam prestando atendimento, convidálas a participar do estudo e todas concordaram. Foi rea- 
lizado contato telefônico com as outras catorze mulheres, tanto para convidá-las para o estudo, quanto para saber se estavam recebendo assistência em outra instituição e, em caso negativo, convidá-las para o Grupo de Adesão ao Tratamento que estava sendo iniciado no CR. Porém as tentativas foram fracassadas, visto que os telefones de contato estavam errados ou elas já tinham mudado de residência ou de trabalho. Conseguimos contato apenas com uma delas, que estava morando e fazendo tratamento em outro Estado e que demonstrou muito interesse em participar da pesquisa. Ela veio para São Paulo e foi entrevistada. Cabe acrescentar que todos os prontuários continham a informação por escrito de que elas autorizavam o contato telefônico.

O convite para as profissionais do sexo soronegativas foi feito no Grupo de Prevenção pelo Educador em Saúde e pela Assistente Social. Foi enfatizado que a recusa não alteraria a qualidade do seu atendimento no serviço. O objetivo do estudo foi informado, sendo então acertados dia, local e duração aproximada da entrevista.

A princípio, a entrevista seria em grupo por estar mais de acordo com o referencial teórico adotado. Cinco mulheres verbalizaram interesse em participar, mas queriam que fosse individualmente. Algumas quiseram participar do grupo, mas, no dia e horário combinado, não compareceram. Foram feitas mais duas tentativas, mas todas infrutíferas. Já as 5 mulheres que manifestaram interesse em participar individualmente, compareceram no dia e horário estabelecidos, sendo então realizadas as cinco entrevistas.

A prerrogativa de realizar as entrevistas individualmente por parte das entrevistadas será analisada mais profundamente no tópico "Resultados e Discussão".

No dia, local e horário combinados, o objetivo da pesquisa foi reiterado, o termo de consentimento e a autorização da gravação lidos e assinados, e enfatizada a liberdade de recusar-se a responder qualquer pergunta ou mesmo a continuar participando da entrevista.

\section{Procedimentos de análise}

Foi utilizada a técnica da análise temática, identificando e analisando os núcleos de significado de cada discurso, contextualizando-os ao processo material e histórico que os constituiu. Através de leituras sistemáticas do material, foram destacados temas que emergiram pela freqüência, pelas emoções desencadeadas, pelas ambivalências e pela relevância para a compreensão do objetivo da pesquisa. Os temas foram analisados e interpretados com base tanto no conjunto quanto individualmente. Os discursos foram contextualizados com a história de vida das entrevistadas, de modo a serem apreendidos de forma abrangente e profunda. Partiu-se do pressuposto de que a linguagem é histórica e se expressa no cotidiano, havendo uma relação indissociável entre linguagem e ação (Minayo, 1996).

Minayo (1996) ressalta que, para se fazer uma análise temática, devem ser detectados os núcleos de sentido que compõem uma comunicação na qual a presença de determinados temas reflete os valores de referência e os mode- los de comportamento presentes no discurso.

Os dados não podem ser analisados de forma isolada. Ao serem criados os núcleos de significação, deve-se ter o cuidado de observar a apropriação dos conteúdos expressos pelos sujeitos, de modo a não fragmentar o discurso. Aguiar (2001, p. 137), por sua vez, observa que se devem “. . . separar os núcleos de significação para em seguida reintegrá-los no seu movimento para, aí sim, apreendêlos de forma mais global e profunda”.

\section{Resultados e Discussão}

\section{Tema 1 - Família como Desencadeadora e Mantedora da Atividade de Profissional do Sexo}

As entrevistadas atribuíram problemas intrafamiliares como os responsáveis por sua saída de casa e entrada na prostituição como conseqüência dessa situação. $\mathrm{O}$ valor da remuneração recebida foi apontado como o principal atrativo da atividade e como meio de sustento dos filhos. Ou seja, a família de origem seria a desencadeadora da entrada na prostituição e os filhos seriam os responsáveis pela permanência nesta. Como se pode observar, a questão financeira é colocada com a "principal causadora" do início da atividade de Profissional do Sexo. Contudo, além da relação "causa-efeito" ser muito simplista, ao se considerar a realidade econômica da maioria das pessoas, com certeza deveria haver um número muito mais elevado de Profissionais do Sexo no País. Podemos pensar que esta atividade é uma forma de garantir seu sustento e o da família bem acima dos padrões a que outras mulheres em suas condições socioeconômicas teriam, fazendo com que o núcleo familiar mantenha-se coeso. Daí a repetição, nos discursos, das razões de sustento familiar como justificativa para início e permanência de suas atividades. Além de dar-lhes maior destaque dentro da família, a prostituição também pode ser vista como um meio de negação dos papéis atribuídos às mulheres pela sociedade, como aponta Brigagão (1998). A remuneração do trabalho proporciona uma mudança no lugar da Profissional do Sexo dentro da família. Antes, elas estavam "à margem” da família e passaram a ser o "centro", ou seja, a atividade contribuiu para a elevação do seu status dentro da família, levando-as, então, a exercer o papel de provedoras.

Todas ocupam papel de destaque no sustento familiar, porém, em alguns casos, a origem da remuneração é omitida. Para Castro (1995), o que de fato ocorre é que os familiares fingem que não sabem. Acabam fazendo um acordo implícito para manterem os valores burgueses sobre a família, e, ao mesmo tempo, poderem usufruir de bens que seriam inacessíveis sem esta atividade.

"Minha mãe me expulsou de casa. Tinha que dormir num galpão. Foi quando li no jornal que estavam precisando de garotas simpáticas para acompanhar executivo. Agora sou eu que sustento meus pais e meus filhos com meu dinheiro sujo" (E., 30 anos, soronegativa). 
Tema 2 - Identidades Diversas nos Diferentes Ambientes Freqüentados - Cisão Trabalho X Afetividade

A assunção de identidades diferentes, de acordo com os valores do espaço ocupado, assemelha-se à "divisão dos mundos" salientada por Castro (1995). A distinção entre o "mundo de dentro" e o "mundo de fora" da prostituição é uma regra comum nesse contexto, sendo comumente expressado através da duplicidade de nome da Profissional do Sexo, o tal "nome de guerra".

As "diversas identidades", ao propiciarem a cisão entre o trabalho e a afetividade, também podem comprometer a prevenção do HIV e da AIDS. O preservativo é tido como instrumento de trabalho para as Profissionais do Sexo. As entrevistadas relataram ter sido bem orientadas pelos gerentes das casas e donos dos bares e hotéis quanto ao uso do preservativo no trabalho. Contudo, ao se relacionar afetivamente com alguém, o uso do preservativo pode ser visto como um "marco divisor" entre o trabalho e a afetividade. Explicando melhor, o uso do preservativo pode estar associado ao trabalho e, para a separação entre ele e a vida afetiva ser bem estabelecida, na ocasião de um envolvimento amoroso, ele pode ser dispensado.

Essa cisão na identidade é sentida como um "mecanismo de defesa" para preservar os outros espaços de sua vida. Contudo, ela acaba ocasionando uma abdicação da esfera amorosa. Apenas duas entrevistadas conseguiram manter um relacionamento conjugal concomitante ao exercício de suas atividades. Porém, foi possível observar que esses relacionamentos eram extremamente marcados por uma exploração financeira pelos seus parceiros. Podemos inferir que elas precisavam "pagar um preço” para mantê-las. Pelo fato das Profissionais do Sexo divergirem do padrão esperado para o sexo feminino, o senso comum lhes atribui características desviantes, consideradas incompatíveis com a vivência conjugal, que acabam sendo introjetadas por elas e pelas pessoas que com elas convivem, perpetuando este processo (Ministério da Saúde, 2002b). Daí, para conseguirem usufruir de uma relação conjugal, precisam arcar com uma série de "condições", que acabam transformando-a em uma relação de submissão delas perante o companheiro. Além disso, a excessiva preocupação em tentar esconder seu trabalho pode fazer com que não se criem vínculos relacionais mais duradouros, por medo de que sua atividade seja descoberta: "Só penso em ganhar dinheiro. Desde que estou nessa vida, nunca saí com ninguém de graça” (M., 43 anos, soronegativa).

"Quando meu marido soube, sossegou. Não queria mais saber de nenhum serviço. Só ficava em casa comendo, dormindo e fumando às minhas custas" (L., 24 anos, soronegativa).

O fato de não ter sido possível realizar as entrevistas em grupo também reflete sua dificuldade em integrar aspectos afetivos aos relacionados ao trabalho.
Tema 3 - Contradições Vividas acerca do Trabalho

Fonte de sofrimento e de desvalorização x fonte de prazer.

Ao mesmo tempo em que a atividade é vivida com tanto sofrimento a ponto de ser necessária a utilização de alguns subterfúgios para poder ser tolerada, ela também propicia alguns prazeres, difíceis de serem verbalizados.

No início das entrevistas, o trabalho é descrito como humilhante e gerador de sofrimento. Somente após o aprofundamento do vínculo na entrevista e após uma maior reflexão sobre as questões verbalizadas, é que elas tomam consciência e se permitem falar também sobre os prazeres que o trabalho lhes proporciona. Contudo os desprazeres são verbalizados de forma predominante: "É duro ir para a cama com alguém que você nem conhece. Preciso beber muito para encarar" (R., 39 anos, soronegativa).

"Tem clientes que a gente gosta do sexo e quer que volte mais vezes" (M., 43 anos, soronegativa).

\section{Transmissor de doença $x$ promotor de prevenção}

O trabalho é verbalizado como potencial propagador de Doenças Sexualmente Transmissíveis, mas também como oportunidade de divulgar informações e incentivar atitudes que podem promover a prevenção de tais doenças. Neste ponto, a prevenção pelos "pares", que consiste em capacitar lideranças de determinado grupo social para que elas difundam informações referentes às DSTs e HIV de forma horizontal e contextualizada, mostra-se potencialmente eficaz: "Peguei o HIV nesse trabalho maldito" (R., 32 anos, soropositiva).

"Eu converso com eles. Oriento para eles terem cuidado, pois algumas podem ter o vírus, ficar com o dinheiro que eles pagam a mais para transar sem camisinha, e passar o vírus" (L., 24 anos, soronegativa).

\section{Sacrificio em prol dos filhos $X$ atividade "vergonhosa"} para os filhos tomarem conhecimento

Todas as entrevistadas são mães e atribuem sua permanência na atividade de Profissional do Sexo ao fato de ser um meio de ganhar dinheiro para sustentar os filhos. Contudo, ao mesmo tempo em que o trabalho é sentido como um sacrifício em benefício dos filhos, elas confessaram ter vergonha de contar para eles sobre esse trabalho. É certo que esta vergonha de falar sobre a atividade não se refere apenas aos filhos e sim às pessoas de um modo geral.

"Sustento meus filhos com o dinheiro que ganho" (E., 30 anos, soronegativa).

"Meus filhos nem imaginam onde trabalho" (M., 43 anos, soronegativa).

Trabalho digno, merecedor de respeito $x$ desqualificação das pessoas que exercem a atividade

Ocorre uma oscilação na atribuição do trabalho como digno de respeito e como desqualificador das pessoas que o exercem. Elas reivindicam respeito, porém se autodes- 
valorizam. Esta dicotomia dificulta o fortalecimento das Profissionais do Sexo enquanto categoria trabalhista e é reforçada pelas representações sociais da prostituta como "vagabunda" e "delinqüente", que são reproduzidas historicamente.

"A puta dá de graça. Eu cobro pelo meu serviço" (R., 39 anos, soronegativa).

Meio de ser bem remunerada $x$ dinheiro "amaldiçoado"

A atividade é vista como um meio de ganhar dinheiro mais rápido do que em outro tipo de trabalho. Contudo, ao mesmo tempo em que o dinheiro é tido como um meio de atingir os objetivos, elas também o depreciam. A desqualificação que elas atribuem ao trabalho é estendida à remuneração recebida.

"Dá para ganhar mais dinheiro ali do que em outro serviço" (L., 24 anos, soronegativa).

"O dinheiro que recebia era maldito" (R., 32 anos, soropositiva).

Autonomia e liberdade x insegurança e submissão.

O não estabelecimento de um vínculo empregatício gera tanto um sentimento de insegurança quanto de liberdade nas trabalhadoras do sexo. Gera insegurança o fato de terem que se submeter a algumas situações sem terem um "espaço" de reivindicações, além de poderem ficar sem rendimento em face do aparecimento de alguma doença ou mesmo devido à ausência de clientes. Contudo o fato de não serem obrigadas a cumprir horário e terem, aparentemente, a liberdade de faltar ao trabalho sem nenhuma sanção são considerados grandes atrativos da atividade.

"A gente pode folgar o dia que quiser" (N., 21 anos, soronegativa).

"Os clientes acham que a prostituta é obrigada a aceitar tudo que eles querem" (A., 50 anos, soropositiva).

\section{Solidariedade e competição}

Os vínculos estabelecidos entre as colegas de trabalho são descritos como solidários e competitivos. Esta descrição não é peculiar às Profissionais do Sexo, estendendo-se para a sociedade de um modo geral, sendo também observada em outros ambientes de trabalho.

É interessante observar a pluralidade de sentidos no discurso das entrevistadas, conforme apontado por Brigagão (1998), e como a carga de preconceitos historicamente atribuídos à prostituição acaba refletindo-se no modo de pensar e no discurso das Profissionais do Sexo, contribuindo para o surgimento de sentimentos ambiva-lentes e contraditórios sobre a atividade. Ao mesmo tempo em que o trabalho é visto como forma de serem mais bem remuneradas do que em outras atividades, o dinheiro recebido é encarado como "maldito" e logo acabará. As entrevistadas falam do quanto "suam" para ganhar o dinheiro e, ao mesmo tempo, ressaltam que ele vem "fácil”. São solidárias, mas também competitivas. É claro que as relações humanas são marcadas por contradições. Contudo, ao não se apropriarem dessas contradições, a possibilidade de superação fica restrita, aumentando o processo de alienação.

Cabe salientar que essa ambivalência foi mais observada nas Profissionais do Sexo soronegativas, as quais continuam exercendo a atividade. É cer to que, em todas as profissões, existem aspectos agradáveis e desagradáveis, em maior ou menor grau. O que mais chama a atenção, porém, é a polarização dos discursos das Profissionais do Sexo soropositivas, os quais apenas enfatizavam os desprazeres do trabalho, que foram tão intensos que desencadearam a saída dessas mulheres de sua atividade.

Tema 4-AIDS como Fator Limitante dos Prazeres em suas Vidas e como Empecilho para a Continuidade do Exercício de suas Atividades

As quatro entrevistadas que são portadoras do vírus do HIV abandonaram a atividade após a aquisição da AIDS. Podemos inferir que a saída do trabalho está intrinsecamente relacionada ao processo de adoecimento. É interessante observar que, por ocasião do diagnóstico e algum tempo depois, as entrevistadas soropositivas continuaram exercendo a atividade de Profissional do Sexo, fazendo uso do preservativo como instrumento de trabalho e proteção. Com as perdas advindas da doença (herpes labial, infecção genital recorrente), o sofrimento já existente na prática profissional se intensificou a ponto de não conseguirem mais trabalhar. $\mathrm{O}$ abandono do trabalho significou uma diminuição importante na remuneração, sendo insuficiente para o sustento da família.

O abandono da atividade após o adoecimento ocasionado pela AIDS não é peculiar às Profissionais do Sexo, mas diz respeito à população em geral. Vermelho, Barbosa e Nogueira (1999) constatam que apenas 30\% das mulheres soropositivas entrevistadas que participavam do mercado de trabalho conseguiram retornar a ele após a infecção pelo HIV.

Alves (2001) conclui que o profissional soropositivo pode continuar exercendo suas atividades enquanto estiver em condições físicas e psicológicas para tal, desde que utilize os equipamentos de biossegurança. A autora também observa que o abandono da atividade profissional pode representar um comprometimento na saúde mental (sem falar na questão financeira e suas conseqüências) no indivíduo. No caso das entrevistadas, se, de um lado, sua saída desestruturou seu sustento e sua vida, por outro, a continuidade também poderia desencadear uma ruptura em sua saúde mental e ter conseqüências ainda mais severas. Nesse sentido, é uma atitude saudável a percepção e o respeito demonstrados pelo seu limite de tolerância.

"Ainda continuei trabalhando quando soube que era positiva. Mas não deu para continuar. Eles querem beijar na boca e minha boca está toda rachada..." (M., 36 anos, soropositiva).

A AIDS foi associada pelas entrevistadas a sentença de morte; doença do outro; sexualidade; perdas; causalidade divina; 
horror e forma de vingança. Tais associações estão de acordo com as metáforas encontradas no estudo de Parker e Aggleton (2001). Contudo a AIDS também foi associada a fonte de felicidade, assistência e autonomia. Paradoxalmente, para uma das entrevistadas, algo que é associado à morte, trouxe a vida para ela A partir dos ganhos secundários advindos da doença, esta entrevistada passou a se sentir cidadã, passou a lutar por seus direitos e a buscar as soluções para seus problemas, não mais encarando a morte como única opção.

Com os avanços do tratamento, melhoria da assistência e cronificação da doença, estudos apontam para uma "banalização" da epidemia, o que também compromete práticas preventivas. Melchior (2000) observa que, com a repercussão da eficácia dos medicamentos anti-retrovirais (ARV), foi observado um descuido na prevenção da AIDS. Os ganhos secundários da doença (auxílio financeiro, assistência médica de melhor qualidade) verbalizados por esta entrevistada, comparados à situação de exclusão social vivenciada por muitas pessoas, também podem contribuir para a "banalização" da doença. Não defendemos o ponto de vista de que se deva diminuir os benefícios aos portadores do HIV, mas melhorar as condições de vida da população em geral.

As entrevistadas soropositivas relataram mudanças nas representações da AIDS entre o momento do diagnóstico e atualmente. Estas mudanças também foram verbalizadas pelas entrevistadas soronegativas, após conhecerem e conviverem com pessoas portadoras do vírus ou após freqüentarem o Grupo de Prevenção do CR Santo Amaro. A partir do momento em que houve uma maior aproximação, convivência e consciência de questões relacionadas ao HIV/ AIDS por parte das entrevistadas, ocorreu um processo de desconstrução de idéias arraigadas sobre o vírus e a doença, simultâneo ao de construção de novos significados.

\section{Tema 5 - Fatores Associados ao Aumento da Vulnerabilidade} ao HIV

O HIV é muito temido no ambiente de comercialização do sexo, pois uma de suas vias de transmissão é a sexual. Apesar do uso correto do preservativo evitar a contaminação, a maioria das entrevistadas contou episódios em que ocorreu o seu rompimento ou a não-utilização. Elas falaram sobre o processo de conscientização da importância de seu uso e do paradoxo de, em algumas ocasiões, não utilizá-lo de forma efetiva.

Foi também identificada uma relação de poder do cliente em relação à Profissional do Sexo. Isso pode estar reproduzindo os valores da sociedade pós-moderna que, de acordo com Baudrillard (1995), é regida pelas leis de mercado. Sendo assim, a Profissional do Sexo passa a ser vista como uma mercadoria que se deve adequar às exigências do consumidor (cliente). Nessa perspectiva, o poder de negociação da Profissional do Sexo é reduzido, aumentando sua vulnerabilidade ao HIV.

Aliados às exigências do consumidor, o aumento do desemprego no País, a concorrência e a competitividade do mercado também dificultam um maior fortalecimento das profissionais do sexo, sua organização como classe e a luta pelos seus direitos.

Outro ponto que merece destaque é a brevidade do seu trabalho. Afirmam que, com o avançar da idade, essas Profissionais do Sexo, são preteridas pelas mais jovens, entrando em decadência. Isso reflete os valores da sociedade atual, a qual "cultua" a beleza e a juventude, "descartando" as pessoas que não se adequam ao padrão imposto.

A "vida curta" da atividade faz com que as Profissionais do Sexo maximizem seus ganhos nesse período. Contudo a ânsia de ganhar muito dinheiro em pouco tempo pode favorecer práticas sexuais desprotegidas, pelo fato destas serem melhor remuneradas. A atividade de Profissional do Sexo é sentida como transitória por todas as entrevistadas. Ela é vista como um meio para atingir seus objetivos e todas afirmaram que a deixará assim que conseguir atingi-los. Nessa perspectiva, elas não conseguem assumir-se como Profissionais do Sexo, mas se sentem como pessoas que, no momento, estão comercializando sexo. Esta observação é importante, pois elas só vão conseguir lutar pelos seus direitos quando se organizarem enquanto categoria, e isso só será possível quando se considerarem pertencentes a esta categoria. Apesar do Ministério do Trabalho já ter incluído, no ano de 2002, a categoria profissional do sexo na Classificação Brasileira de Ocupações (Ministério do Trabalho, 2003), em São Paulo, maior cidade do País, não há registro de nenhuma associação até a presente data. Cabe salientar que a identidade não é "colada" na atividade, ou seja, a pessoa não se resume ao que faz, contudo a identidade refere-se à constituição do indivíduo no processo de desenvolvimento da consciência em relação à atividade (Gonçalves \& Bock, 2003). Sendo assim, a dissociação entre identidade e atividade impede o desenvolvimento da consciência, propiciando a alienação.

O caráter provisório da atividade, porém, se prolonga por tempo indeterminado, visto que, na maioria das vezes, a saída do trabalho provoca um rebaixamento excessivo de sua remuneração. Dessa forma, elas nem deixam de pertencer a esta categoria nem conseguem se organizar enquanto tal, evidenciando a contradição entre suas falas e a ação efetiva.

Essa transitoriedade foi também observada por Adorno, Castro, Vianna, Faria e Silva (1997), ao fazerem um levantamento do repertório sobre sexualidades existentes na Fundação Estadual do Bem-Estar do Menor de São Paulo (FEBEM/SP). Os autores relatam que as constantes transferências e a expectativa de saída da instituição faziam com que os adolescentes se sentissem em uma situação transitória, comprometendo um plano de trabalho mais efetivo a médio e longo prazo com esta população. Associam essa transitoriedade à efemeridade e à fragmentação da sociedade contemporânea.

As profissionais do sexo entrevistadas que abandonaram sua atividade queixaram-se bastante de sua situação financeira atual. É possível, então, inferir que são poucas as profissionais do sexo que conseguem manter um ga- 
nho satisfatório, após sua saída da atividade, o que nos pode direcionar para um trabalho voltado para algumas ações de promoção à saúde, entendendo esta como qualidade de vida. Além disso, sugerimos a realização de cursos profissionalizantes de curta duração na área de economia, administração e contabilidade, como forma de propiciar uma melhor gerência de seus ganhos, além de permitirem a instrumentação daquelas que desejarem abrir seu próprio negócio. Contudo não se pode perder de vista que o desejo de sair desta atividade é bastante impulsionado pelas representações sociais pejorativas da prostituição. Neste sentido, a confrontação e a superação dessas representações também devem ser metas do trabalho da prevenção da assistência desta população.

Paradoxalmente, assim como a saída é impulsionada pelas representações sociais, sua entrada é influenciada pelas "leis de mercado" da sociedade em que vivemos. No último censo do Instituto Brasileiro de Geografia e Estatística (IBGE, 2000), 76,5\% das pessoas que tinham um trabalho, haviam concluído o ensino fundamental; as mulheres representavam 25,7\% dos ocupados entre os empregadores e os trabalhadores por conta própria e a maioria entre os não remunerados (52,2\%). A remuneração média familiar no Sudeste girou em torno de $\mathrm{R} \$ 700,00$ (setecentos reais), contudo três quartos do grupo de pessoas que ganhavam até um salário mínimo não tinham concluído o ensino fundamental ou equivalente (IBGE, 2003). Estes dados contrastam com a remuneração recebida pelas profissionais do sexo que continuam na atividade. Apenas uma concluiu o segundo grau e seus ganhos giram em torno de $\mathrm{R} \$$ 1.500,00 a $\mathrm{R} \$ 3.000,00$ (mil e quinhentos a três mil reais). $\mathrm{A}$ atividade proporciona ganhos bem superiores ao de mulheres em condições sócio-demográficas semelhantes.

A discussão das questões mercadológicas da sociedade pós-moderna e da ideologia a elas subjacente deve ser levada em conta na prevenção das Doenças Sexualmente Transmissíveis e da AIDS.

O uso do preservativo é visto como um inconveniente para alguns clientes, que remuneram com um valor acima do estabelecido a Profissional do Sexo que não o utiliza. A não-utilização do preservativo aparece como uma "opção" da profissional do sexo em faturar mais dinheiro, enquanto, em algumas ocasiões, a exigência do preservativo representa a perda do cliente e do dinheiro que o programa proporcionaria.

Algumas entrevistadas verbalizaram ter aprendido a negociar a utilização do preservativo. Este processo de aprendizagem de negociação vivenciada pelas entrevistadas demonstra que a argumentação e o convencimento podem ser aprendidos e, conseqüentemente, promovidos. Este dado é muito importante para a prevenção de doenças sexualmente transmissíveis, pois, junto à questão mercadológica, a relação assimétrica de poder entre o gênero masculino e feminino também age como empecilho ao uso de preservativo. Isto diz respeito não somente às profissionais do sexo, mas às mulheres de um modo geral. Não é "por acaso" que a contaminação pelo HIV tem aumentado na população feminina. Sendo assim, torna-se essencial promover o poder de negociação nas mulheres. Isso está de acordo com as idéias de Mane e Aggleton (1999), que defendem a "desnaturalização" da desigualdade entre homens e mulheres e a conscientização da dimensão cultural e histórica na diferença entre o gênero feminino e o masculino. Afirmam que discussões mais amplas sobre poder e relações de gênero são mais eficazes que o mero ensino de "técnicas", pois, a partir de uma maior consciência das divisões sexuais e das desigualdades de gênero, a mulher pode adquirir maior poder em suas relações sociais e sexuais com os homens, diminuindo sua vulnerabilidade às doenças sexualmente transmissíveis e ao HIV.

"Tem homens que colocam o pinto de qualquer jeito, com força e muito rápido. Aí a camisinha estoura" (M., 43 anos, soronegativa).

"Tem coisas que não faço. Mas a concorrência é muito grande. Se não faço, outra faz e ganha o cliente" (N., 21 anos, soronegativa).

\section{Tema 6 - Serviço de Saúde como Facilitador do Processo de Adesão ao Tratamento}

Apesar de todas relatarem uma boa relação com o serviço de saúde, pôde-se observar uma certa diferenciação entre as profissionais do sexo soropositivas e as soronegativas no que se refere à vinculação a esse serviço

As entrevistadas soronegativas elogiaram muito o Grupo de Prevenção, o atendimento médico e aquele efetuado pela equipe multiprofissional. Elas relataram gostar muito do cuidado com que são examinadas, do vínculo estabelecido com os profissionais e do canal de comunicação que possibilita o esclarecimento de dúvidas e aprendizado.

A flexibilidade do agendamento e a possibilidade de não virem a alguns encontros do grupo sem serem dele excluídas são apontadas como fatores de aderência ao serviço. Esses dados são congruentes com a valorização da liberdade em suas vidas, salientada em vários trechos das entrevistas. A vinculação com o profissional de saúde e a qualidade do atendimento foram referidas como peculiares ao Centro de Referência, o que deveria estar presente em qualquer serviço, seja ele público ou particular. A satisfação com a unidade faz com que elas tragam outras pessoas, além de divulgarem informações e atitudes aprendidas, multiplicando o alcance da prevenção e da assistência.

Ficou patente, além disso, uma nítida associação entre a receptividade do serviço e a adesão ao tratamento, principalmente no que se refere ao primeiro contato com a unidade de saúde. No que se refere ao HIV/AIDS, Melchior (2000) aponta a importância de um investimento no vínculo dos profissionais com as pessoas assistidas, principalmente no começo do tratamento, visto que é neste momento que se concentra o período de alguma aderência dos não aderentes e de momentos de não aderência dos mais aderentes, normalmente ligados às dificuldades iniciais. Por isso, o início de tratamento é de fundamental importância, pois apesar de ser um momento delicado e que exige algumas mudanças no cotidiano do indivíduo, 
também é o momento em que a adesão é mais significativa, diminuindo ao longo do tempo. Contudo os autores também observam que uma boa adesão no início do tratamento pode ser indício de uma boa adesão a longo prazo (Jordan, Lopes, Okasaki, Komatsu \& Neme, 2000). Nesse sentido, torna-se imprescindível a garantia de um "acolhimento” de qualidade do usuário pelo serviço de saúde. O acolhimento transcende a boa receptividade e a relação de qualidade entre os profissionais de saúde e os usuários, abrangendo também a resolutividade do serviço e a conveniência dos agendamentos e procedimentos.

As entrevistadas soropositivas apontaram o momento do diagnóstico e o início da medicação anti-retroviral como os mais geradores de sofrimento, contudo, com o apoio recebido pela equipe multiprofissional, tais momentos puderam ser suportados e superados. Infelizmente, não foi possível contactar as que não continuaram no Serviço. Poderíamos ter identificado fatores importantes de nãoadesão ou mesmo constatar que elas estavam em tratamento em outra unidade de saúde. Por outro lado, este episódio propiciou uma revisão no modo como eram preenchidos os dados de identificação dos usuários novos na unidade de saúde, passando-se a fazê-lo num local de maior privacidade, de forma mais individualizada, explicando a importância da veracidade dos dados e a garantia do sigilo institucional.

Pudemos observar que os profissionais responsáveis pelo atendimento estabeleceram um bom canal de comunicação com as entrevistadas. Melchior (2000) ressalta que a possibilidade de comunicação e negociação com a equipe de saúde é fundamental na superação das dificuldades.

As quatro entrevistadas soropositivas, além do atendimento médico, também puderam contar com o atendimento psicológico e o do Serviço Social. Di Girólamo (2000) observa que o atendimento psicológico e o do serviço social, aliado ao atendimento médico, aumentam significativamente a aderência do usuário ao serviço de saúde. $\mathrm{O}$ atendimento multiprofissional tem sido um grande aliado, não somente na adesão como também no grau de satisfação e resolutividade. Esposito, Labaki, Palhares e Santos (2003) chamam a atenção de que a realização do grupo de prevenção pela equipe multiprofissional, aliado ao atendimento integral efetuado pelas demais especialidades da unidade, reduziram a incidência de Doenças Sexualmente Transmissíveis nas Profissionais do Sexo, assim como proporcionaram um aumento na realização de sorologias (HIV, VDRL, hepatites B e C) e vacinação (hepatite B). Cabe acrescentar que, na unidade aqui referenciada, além dos atendimentos, houve discussões em equipe sobre esses aspectos, confirmando que o diálogo na equipe também pode contribuir para o aprimoramento do canal de comunicação entre os profissionais e os usuários do Serviço.

"Aqui é o único lugar que não existe o preconceito, a discriminação. Aqui todo mundo sabe o que a gente faz e tratam a gente como gente" (R., 39 anos, soronegativa)
"Tive ajuda de profissionais competentes que me deram apoio na hora em que mais precisei" (A., 50 anos, soropositiva).

\section{Tema 7 - Entrevista como Propiciadora de Transformações}

Na Psicologia Sócio-histórica, o processo da pesquisa também deve ser propiciador de intervenções, de modo a aliar a produção do conhecimento com a prestação de serviço à população (Aguiar, 2001).

As entrevistas com as profissionais do sexo foram bastante interativas, propiciando algumas reflexões e transformações. Não podemos deixar de considerar que foi apenas uma única entrevista individual, mas, apesar disso, esta oportunidade de intervenção não foi desperdiçada.

Foi possível observar, nas entrevistadas, um resgate das histórias de vida e uma maior apropriação da identidade. A entrevista foi um momento em que elas se sentiram aceitas e escutadas, podendo "ser elas mesmas". Gonçalves e Bock (2003), partindo de Ciampa, chamam a atenção de que, no processo de construção da subjetividade, ocorre uma relação dialética na coexistência da metamorfose do indivíduo com a sua "mesmice", ou seja, a transformação do indivíduo nele mesmo. Esse processo fica evidente no relato das entrevistadas. Assim, além de um instrumento de pesquisa, a entrevista foi um instrumento propulsor de reflexões e conscientização.

As contradições nos discursos das entrevistadas foram explicitadas e discutidas com elas. A partir da discussão e reflexão, elas puderam tomar consciência e se tornar mais "donas" de sua vida.

As entrevistadas relataram que, ao falarem de sua vida, refletiram sobre seu passado e, dessa forma, seus projetos de vida se tornaram mais claros. Elas puderam dar um contexto histórico em sua vida, no qual passado, presente e futuro se relacionam de forma dinâmica, flexível e dialética.

As entrevistadas também tinham um propósito ao aceitar participar do estudo. Elas queriam que o relato de suas experiências fosse utilizado em benefício de outras pessoas. Chamou atenção o fato de serem as soropositivas as mais preocupadas com o alcance social de sua entrevista. Isto pode ser associado ao engajamento político observado em grande número de indivíduos portadores do HIV.

"Sou acostumada a mentir e hoje falei a verdade. Pude falar da minha vida de verdade e não precisei ficar inventando outras vidas" (N., 21 anos, soronegativa).

"Estou me sentindo aceita pelo que verdadeiramente sou, sem precisar ter que mentir ou agradar para ser aceita" (L., 24 anos, soronegativa).

"Me senti muito bem participando e espero que com essa entrevista eu possa estar ajudando outras pessoas que estão passando pelo que passei” (M., 36 anos, soropositiva).

\section{Conclusões}

A partir da proposta de investigação desta pesquisa, mediante as entrevistas realizadas, foi possível identificar diretrizes para subsidiar um programa de intervenção no 
Centro de Referência em DST/AIDS de Santo Amaro, de modo a contribuir para melhoria da assistência às profissionais do sexo soropositivas e sua adesão ao serviço.

Ficou evidente, neste trabalho, uma nítida diferenciação nas atribuições qualificadoras da atividade de Profissional do Sexo entre os discursos das entrevistadas soropositivas e as soronegativas. As verbalizações destas eram repletas de contradições acerca de sua atividade, havendo uma pluralidade de sentidos na vivência do seu trabalho. Já os discursos das entrevistadas soropositivas eram polarizados nos desprazeres da atividade e na inviabilidade de sua continuidade. No primeiro caso, a carga de preconceitos historicamente atribuídos à prostituição acaba refletindose no modo de pensar e no discurso das Profissionais do Sexo, contribuindo para o surgimento de sentimentos ambivalentes e contraditórios. No caso das entrevistadas soropositivas, o HIV não é visto como empecilho para o exercício da atividade, contudo o processo de adoecimento desencadeado pela AIDS propriamente dita é sentido como incompatível com a continuidade do trabalho, assim como em outras profissões.

O abandono da atividade em decorrência da AIDS é experimentado como mais uma perda relevante ocasionada pela doença, acrescido ao fato de, na maioria dos casos, diminuir o poder aquisitivo e comprometer o sustento e a qualidade de vida.

As representações sociais da AIDS sofreram modificações entre o momento do diagnóstico e o momento atual, no caso das soropositivas. Estas mudanças também foram sentidas pelas entrevistadas soronegativas após conhecerem e conviverem com pessoas portadoras do vírus ou após freqüentarem o CR Santo Amaro. A partir do momento em que houve uma maior aproximação, convivência e consciência de questões relacionadas ao HIV/AIDS por parte das entrevistadas, ocorreu um processo de desconstrução de idéias arraigadas sobre o vírus e a doença, simultâneo ao de construção de novos significados. O serviço e os profissionais de saúde também contribuíram para este processo.

Apesar de todas as entrevistadas estarem vinculadas ao serviço de saúde, as Profissionais do Sexo soronegativas referiram melhor acolhimento e maior resolutividade às suas demandas. Este dado aponta para a necessidade de melhoria da assistência às Profissionais do Sexo soropositivas. O Grupo de Prevenção foi considerado um fator estimulador na adesão ao serviço de saúde pelas Profissionais do Sexo soronegativas. Faz-se aqui a sugestão de um Grupo Psicoterapêutico para as Profissionais do Sexo soropositivas, aliado ao atendimento integral e integrado efetuado pelas demais especialidades. Existe, também, a necessidade de um trabalho mais individualizado com as Profissionais do Sexo do CR Santo Amaro, além do trabalho de prevenção coletiva que já é desenvolvido atualmente.

A cisão na identidade observada nas Profissionais do Sexo soronegativas e seus esforços em tentarem esconder seu trabalho dificultam o estabelecimento de vínculos relacionais mais duradouros fora do ambiente de trabalho, contribuindo para formação de guetos espaciais, favorecendo a exclusão social das Profissionais do Sexo.

A assimetria de poder entre os gêneros, os valores da sociedade pós-moderna, que é regida pelas leis de mercado, a vivência da atividade como algo transitório e a fragilidade do contrato de trabalho das Profissionais do Sexo foram considerados fatores enfraquecedores do poder de negociação da categoria, aumentando a vulnerabilidade ao HIV. Salienta-se a necessidade dos serviços que trabalham com essa população, promoverem uma maior apropriação da atividade pelas Profissionais do Sexo, de modo a propiciar movimentos reivindicatórios da categoria pela melhoria das condições de trabalho, diminuindo o sentimento de desprazer em relação à atividade, coibindo possíveis abusos, além de diminuir a vulnerabilidade para DSTs, HIV e AIDS.

As entrevistas realizadas, utilizando o referencial teórico-técnico da Psicologia Sócio-histórica, também propiciaram uma maior reflexão, consciência e apropriação pelas entrevistadas de sua subjetividade e de sua vida.

\section{Referências}

Adorno, R., Castro, A., Vianna, R., Faria, M., \& Silva, S. (1997). Espelhos e imagens: Um levantamento do repertório sobre sexualidades existente na FEBEM/SP. Revista Brasileira de Crescimento e Desenvolvimento Humano, 7(2), 77-83.

Aguiar, W. (2001). A pesquisa em psicologia sócio-histórica: Contribuições para o debate metodológico. In A. M. Bock, M. G. Gonçalves, \& O. Furtado (Eds.), Psicologia sócio-histórica: Uma perspectiva crítica em psicologia (pp. 129-140). São Paulo, SP: Cortez.

Alves, E. G. (2001). O cirurgião-dentista e outros profissionais de saúde portadores de HIV/AIDS: Considerações bioéticas e psicológicas. Dissertação de Mestrado não-publicada, Curso de PósGraduação em Odontologia, Universidade de São Paulo, SP.

Barros, M. (2002). Adolescência e AIDS. In M. Contini, S. Koller, \& M. Barros (Eds.), Adolescência e Psicologia: Concepções, práticas e reflexões críticas (pp. 99-111). Brasília, DF: Conselho Federal de Psicologia.

Baudrillard, J. (1995). A sociedade de consumo. Rio de Janeiro, RJ: Elfos.

Brigagão, J. I. (1998). Prostitutas no Jardim da Luz: Dor e prazer na batalha da sobrevivência. Tese de Doutorado não-publicada, Curso de Pós-Graduação em Psicologia, Universidade de São Paulo, SP.

Castro, R. V. (1995) As representações sociais da pros-tituição na Cidade do Rio de Janeiro. In M. J. Spink (Ed.), O conhecimento no cotidiano: As representações so-ciais na perspectiva social. (pp. 149-187). São Paulo, SP: Brasiliense.

Di Girólamo, M. (2000). Influência do Serviço de Saúde na adesão dos usuários portadores de HIV/AIDS do Centro de Referência de DST/AIDS Jardim Mitsutani no Município de São Paulo. Dissertação de Mestrado não-publicada, Curso de Pós-Graduação em Saúde Pública, Universidade de São Paulo, SP.

Esposito, A. P., Labaki, M. A., Palhares, E. M., \& Santos, C. M. (2003, abril). Avaliação do grupo das profissionais do sexo do Centro de Referência DST/AIDS de Santo Amaro em relação à prevenção de DST/AIDS. Trabalho apresentado no II Foro en VIH/SIDA/ITS de América Latina y el Caribe, Havana, Cuba. 
Gonçalves, M. G., \& Bock, A. M. (2003). Indivíduo-sociedade: Uma relação importante na Psicologia Social. In A. M. Bock (Ed.), A perspectiva sócio-histórica na formação em Psicologia (pp. 41-99). São Paulo, SP: Vozes.

Guerra, M. A., Veras, M. A., \& Ribeiro, A. F. (2002). Epidemiologia. In R. Veronesi, \& R. Focaccia (Ed.), Tratado de Infectologia (pp.88-99). São Paulo, SP: Atheneu.

Instituto Brasileiro de Geografia e Estatística. (2003). Censo Demográfico 2000: Trabalho e rendimento. Retirado em dezembro de 2003, de http://www.ibge.gov.br

Jordan, M., Lopes, J., Okasaki, E., Komatsu, C., \& Nemes, M. (2000). Aderência ao tratamento anti-retroviral em AIDS: Revisão da literatura médica. In P. R. Teixeira, V. Paiva, \& E. Shimma (Eds.), Tá difícil de engolir? Experiências de adesão ao tratamento anti-retroviral em São Paulo (pp. 5-25). São Paulo, SP: Nepaids.

Kahhale, E. M. P. (2003). Psicologia na saúde: Em busca de uma leitura crítica e de uma atuação compromissada. In A. M. Bock (Ed.), A perspectiva sócio-histórica na formação em psicologia (pp. 161-191). São Paulo, SP: Vozes.

Mane, P., \& Aggleton, P. (1999). Gênero e poder: Comunicação, negociação e preservativo Feminino. In R. Barbosa, \& R. Parker (Eds.), Sexualidades pelo avesso: Direitos, identidades e poder (pp. 215-228). Rio de Janeiro, RJ: Editora 34.

Melchior, R. (2000). Avaliação da aderência de usuários do Sistema Público de assistência ao tratamento de AIDS: Uma análise qualitativa. Dissertação de Mestrado não-publicada, Curso de PósGraduação em Saúde Pública, Universidade de São Paulo, SP.

Minayo, M. C. (1996). O desafio do conhecimento: Pesquisa qualitativa em saúde (4. ed.). São Paulo, SP: HUCITEC.

Ministério da Saúde. (2002a). AIDS-Boletim Epidemiológico. Brasília, DF: Autor.

Ministério da Saúde. (2002b). Profissionais do sexo: Documento referencial para ações de prevenção das DSTs e da AIDS. Brasília, DF: Coordenação Nacional de DST e AIDS.

Ministério do Trabalho. (2003). Classificação brasileira de ocupações. Retirado em maio de 2003, de http://www.mtb.gov.br/ cbo/profissionais do sexo

Parker, R., \& Aggleton, P. (2001). Estigma, discriminação e AIDS. Rio de Janeiro, RJ: Associação Brasileira Interdisciplinar de AIDS.

Secretaria Municipal de São Paulo. (2003). Boletim Epidemiológico de AIDS do Município de São Paulo. São Paulo, SP: Coordenação de DST/AIDS.

Vermelho, L., Barbosa, R., \& Nogueira, S. (1999). Mulheres com AIDS: Desvendando histórias de risco. Cadernos de Saúde Pública, 15(2), 369-379. 